\title{
Teaching Introductory Chemistry Online: The Application of Socio-Cognitive Theories to Improve Students' Learning Outcomes
}

\author{
Manyu Li ${ }^{1, *,+(\mathbb{D})}$, Yu Wang ${ }^{2,3, *(\mathbb{D})}$, Heather N. Stone ${ }^{4}(\mathbb{D})$ and Nadia Turki $^{1}$ \\ 1 Department of Psychology, University of Louisiana at Lafayette, Lafayette, LA 70504, USA; \\ nadia.turki1@louisiana.edu \\ 2 Department of Chemistry, University of Louisiana at Lafayette, Lafayette, LA 70504, USA \\ 3 Institute for Materials Research and Innovation, University of Louisiana at Lafayette, \\ Lafayette, LA 70504, USA \\ 4 Department of Educational Curriculum and Instruction, College of Education, University of Louisiana at \\ Lafayette, Lafayette, LA 70504, USA; heather.stone@louisiana.edu \\ * Correspondence: manyu.li@louisiana.edu (M.L.); yuwang@louisiana.edu (Y.W.) \\ + Current address: Department of Psychology, 104 E University Ave, P.O. Box 43644, Lafayette, LA 70504, USA.
}

check for updates

Citation: Li, M.; Wang, Y.; Stone, $\mathrm{H}$. N.; Turki, N. Teaching Introductory Chemistry Online: The Application of Socio-Cognitive Theories to Improve Students' Learning Outcomes. Educ. Sci. 2021, 11, 95. https://doi.org/ 10.3390/educsci11030095

Academic Editor: Eleanor Dommett

Received: 7 Februaray 2021

Accepted: 23 Februaray 2021

Published: 27 Februaray 2021

Publisher's Note: MDPI stays neutral with regard to jurisdictional claims in published maps and institutional affiliations.

Copyright: (c) 2021 by the authors. Licensee MDPI, Basel, Switzerland. This article is an open access article distributed under the terms and conditions of the Creative Commons Attribution (CC BY) license (https:// creativecommons.org/licenses/by/ $4.0 /)$.
Abstract: The purpose of this randomized experimental study is to apply two socio-cognitive models to understand possible ways to improve students' learning outcomes in an online introductory chemistry learning environment. Specifically, the social presence theory suggested that students' sense of relatedness and learning motivation can be increased by a real or imagined interaction with others. On the other hand, self-regulated learning theory and self-determination theory both suggested that students learn best when they direct their focus to self, rather than others. Using these two theoretical perspectives as the basis, two experimental conditions (social presence vs. self-regulated) were developed in the context of chemistry learning. Participants of the study were randomly assigned to one of the experimental conditions. Both groups were presented with a pre-test, an online micro-lecture on balancing equations, i.e., a subtopic of stoichiometry, and a post-test. Linear mixed model analysis revealed that participants in the self-regulated learning condition had higher improvement in quiz scores than had participants in the social presence condition. Implications of the study and future directions were discussed.

Keywords: chemical education research; introductory chemistry; stoichiometry; distance learning

\section{Introduction}

Learning science online can be challenging to students, especially students in introductory level courses. When students learn science in an online learning environment, they may be placed in an isolated situation, especially when they need to watch video lectures and take notes by themselves [1]. Online learning environment may be drastically different from a classroom situation where students may interact with the instructor and other classmates in real time. Therefore, students' learning outcomes could be impacted negatively when learning in isolation and instructors' efforts in preventing such a sense of isolation is crucial in increasing students' success in online learning [2,3]. In addition, when students are learning in isolation, their motivation to learn may be reduced and their attrition rate may increase, especially when facing difficult concepts [4]. Introductory chemistry is a subject that is often challenging to beginners, thus requiring course design strategies to overcome students' feelings of isolation and the lack of motivation. Therefore, using a double-blind randomized experimental design, this study aimed at examining and comparing the effects of two sociocognitive theoretical framework, social presence theory and self-regulated learning theory (along with self-determination theory) on increasing students' learning outcome in an online chemistry learning environment. 


\subsection{The Role of Peer in Chemistry Learning: Social Presence Theory}

One way in which students' sense of isolation in an online learning environment may be resolved is through an imagined social presence. Social presence theory was developed and applied to address the lack of face-to-face interactions in telecommunication and computer-mediated communication (CMC). Social presence is defined as "the salience of the other in a mediated communication and the consequent salience of their interpersonal interactions" [5]. In other words, social presence is referred to as being aware of others in communications and interactions in CMC. In the smallest occurrence, the social presence is shown in the degree in which a user connects to the intelligence, intentions, as well as the sensory impressions of another user [6]. Social presence is subjective and is impacted by the educational technology implemented [5]. It can be impacted through interactions with peers and instructors through e-mail, discussion boards, and video conferencing. Research studying the effect of social presence in online classrooms found that the real or imagined presence of others is important in strengthening students' sense of relatedness [7], satisfaction [8], and motivation [2]. Social presence can be increased by increasing studentstudent interaction and student-teacher interaction [9], in synchronous class events and asynchronous class events [10], and even in an imagined presence of others [11].

Although social presence theory has not been researched extensively in the context of online chemistry learning, chemical educational research found a significant effect of the role of peer in students' chemistry learning outcome [12-16] in regular, in-person classrooms. For example, in a classroom study examining students in a general chemistry course, when students were asked to discuss concepts learned in class with another student, their chemistry exam scores were significantly higher (i.e., 17.76 percentile points higher) than students who only received traditional lecture-based teaching [12]. Similarly, in another study, learning chemistry with a peer leader was found to result in better critical thinking than a traditional lecture-based approach [13]. Although these studies focused on the in-person classroom, the evidence is clear: Social presence or peer influence is important in chemistry learning.

How can social presence be incorporated in introductory chemistry online course design? Flipped classroom model is a great example of incorporating peer components in chemistry classrooms [17]. The flipped classroom is a teaching strategy that involves having students learn materials online at home, usually watching a video or a simulation. Then, when students come to the classroom, they engage in discussion and problem-solving with the instructor and with one another [18]. For example, in a study examining first-year college students' introductory chemistry classrooms, students being taught in a flipped design classroom were found to have better grades and lower failure rates than students being taught in traditional classrooms [17]. Students also expressed that they preferred a flipped classroom. However, it should be noted that research of the flipped classroom often compares students' outcomes in flipped versus non-flipped classrooms, without identifying what exact components of the flipped design work to improve students learning outcome.

Research looking at specific types of activities or tasks may complement these general findings. For example, one study suggested that giving students' collaborative tasks, such as solving problems together or helping one another to interpret ideas, are helpful for students' learning [10]. Consistent with this idea, a study examining an introductory chemistry laboratory course found that targeting students' helping obligatory (i.e., training students to help other students) was effective in improving college students' attitudes in completing the laboratory course [15]. In another study examining high school students' learning in stoichiometry, simply writing a letter and notes to help younger learners improved students learning outcomes [19]. In other words, studies consistently showed that having students help one another was found to be effective in improving students' learning outcomes. Therefore, in this study, we selected a simple peer interaction task by asking students to help other students learn chemistry by taking notes for them during the video lecture. This procedure was used in a national study on understanding students' learning mindset [20] and was similar to the stoichiometry instruction study [19]. 


\subsection{The Role of Self in Chemistry Learning: Self-Regulated Learning and} Self-Determination Theory

Although classroom studies mentioned in the last section found a significant effect of peer-learning in the chemistry classrooms, randomized controlled trial experiments seem to tell another story. Particularly, the effect of peer-learning has not always been found to be better than the effect of self-learning in chemistry. In a recent randomized controlled trial experiment examining the effect of the flipped classroom (i.e., pre-class online self-learning and then a collaborative group learning), researchers tested the students at different points throughout the learning process to see which flipped classroom activities increased students' chemistry knowledge the most [21]. Surprisingly, results showed that students' chemistry knowledge appeared to increase the most during the pre-class online self-learning, rather than the collaborative group learning [21]. Specifically, the results showed that students in both flipped classrooms and traditional lecture conditions experienced a similar increase in knowledge before and after the self-learning video/in-person lecture. In both conditions, students' improvement was not significant at all between test scores before and after peer collaboration. The researchers concluded that when considering a flipped classroom, the asynchronous instructors should focus on the online self-learning portion. The findings of this study indicate the need to understand the role of the self in online learning. Although the findings may be surprising to people conducting flipped classroom research, the finding is in alignment with sociocognitive perspectives, such as the self-determination theory.

According to self-determination theory, when being placed in a nurturing environment, humans can actively and positively approach goals and grow intellectually, psychologically, and autonomously through effort, commitment and determination [22-25]. Specifically, self-determination theory proposed three basic human needs/motives that enhance human growth, including autonomy, competence, and relatedness [22,24]. Autonomy is being able to be an active agent for manage one's life, competence is being able to master skills and experience the sense of accomplishment through mastery, and relatedness is defined as being able to connect others [22,24]. However, it was also noted that relatedness should not interfere with one's autonomy [22,26]. In educational terms, selfdetermination theory suggested that when being placed in an environment that provides students with resources to learn, students are capable of motivating themselves to achieve goals and to succeed, as long as students experience autonomy (sense of independence and control), competence (sense of mastery), and relatedness (sense of belonging that does not interfere with the sense of independence) in the learning process [27]. Research showed that when college students were given uninteresting learning tasks, perceived autonomy helped to improve students' engagement in the task and their learning outcomes [28]. A qualitative study examining chemistry laboratory students also found that perceived autonomy and competence were keys to designing an effective learning environment for students [29].

Another similar theory is self-regulated learning. Self-regulated learning has been incorporated in chemistry instruction for at least 25 years [30]. There are many different models in self-regulated learning, but the general idea is that students are capable of adopting strategies and taking actions to motivate themselves to achieve goals [31]. Specifically, most models (e.g., the most cited Cyclical self-regulatory phases model [32]) suggested that an effective strategy is to have students engaged in a preparatory stage or forethought phase. This phase involves asking students to set clear goals and develop self-motivation beliefs before learning the materials and performing the learning tasks [31,32]. Then, in the next stage, the performance phase, students engage in self-instruction and self-recording (e.g., note-taking), and attention focusing to improve their learning outcomes [31-33]. Finally, students reflect and evaluate their own performance. The cycle then goes back to the preparatory stage [31,32].

Many online and multimedia educational studies have employed self-determination or self-regulation strategies to improve students' learning. Specifically, self-regulation has 
been a key component in studies that develop chemistry online and multimedia course designs [34,35]. For example, in developing a chemistry self-learning web tool, ChemEd X Data, self-regulation was identified as a key outcome of the tool [36]. Similarly, in developing a stepped supporting tool for students in organic chemistry, researchers found that students saw self-regulation components of the tools to be helpful in understanding chemistry [37]. In another study testing students' self-regulation in learning in a massive open online course (MOOC) on the topic of data science, students' self-regulation was significantly associated with their perception towards the course and their learning outcome in the course [38].

Meta-analyses showed that self-regulated learning significantly predicted better student learning outcomes and performance [33]. Particularly, self-assessment and monitoring strategies (e.g., planning, self-motivating, self-recording/note-taking) were found to be one of the most central self-regulated learning strategies [33]. It was also suggested that this kind of cognitive process helps students understand their way of thinking about chemical knowledge [30]. Therefore, in this study, we selected a simple, brief self-regulation task in which students were asked to motivate themselves and then take notes for themselves. A similar procedure was used in a previous study to understand students' mindsets [20]. These tasks were chosen because they allow a direct comparison between the social presence theoretical model and the self-determination/regulation models.

\subsection{Research Question}

This study aims at studying ways to enhance the effectiveness of online introductory chemistry learning. Specifically, we compared the effect of two learning strategies derived from the social presence theory and from self theories (i.e., self-determination and selfregulated learning theory) on students' online chemistry learning outcomes. Students were presented with online learning materials of an introductory chemistry topic, stoichiometry. A double-blind randomized experimental method was used to reduce experimenter bias and students' social desirability. Students in the social presence condition were asked to write a letter to motivate a peer-learning partner and to take notes to help the student. Students in the self-regulated learning condition (i.e., the condition designed based on self-regulated learning and self-determination theories) participated in a comparable task, that is, to write a letter to encourage themselves and to take notes for themselves to achieve the learning goal. This study was conducted during the beginning of the COVID-19 course transformation period, from an in-person classroom to an online classroom.

The study involved a 2 (conditions) $\times 2$ (time: pre vs. post) design. The present study tested an exploratory research question, "do students in the social presence condition have a better or worse quiz score than students in the self-regulated learning condition"? It was expected that through understanding the research question, specific strategies developed using the two theoretical frameworks could be tested in the context of an introductory, online chemistry learning environment.

\section{Materials and Methods}

\subsection{Sample and Procedure}

The study procedure was approved by the Institutional Review Board (IRB) of the authors' affiliation under the approval code SP20-109 PSYC. College students were recruited from a participant pool in which students could voluntarily participate in different research studies in return for course credits. Upon signing up for the study, students were given a link to participate in the study. The study was hosted on Qualtrics. Students were presented with a consent form and were asked to indicate whether they agreed to participate. Students were told that the study aims to understand their online learning. Students had no knowledge of the experimental conditions of the study. To make sure the learning experience simulated an actual class learning experience, students were told that if they got all answers correct, they would get one additional participation credit (generally 
translating to $1 \%$ of their course grade). If students passed the test with $50 \%$ correct, they would get half participation credit (i.e., translating to $0.5 \%$ of their course grade).

After accepting the consent form, all students were given a quiz to test their stoichiometry knowledge (i.e., pre-test). After completing the pre-test and some survey questions, students were randomly assigned to one of the two conditions. The randomization was performed by Qualtrics randomizer. In both conditions, students engaged in a simple experimental manipulation task before watching the video lecture online.

Specifically, in the social presence condition, students were told that they were selected as a peer mentor for another student learning the material. They were then asked to write a letter to encourage the student. This methodology was previously used in a mindset study in educational contexts [20] and in a chemistry educational study [19]. Subsequently, the students were told to type notes to the student based on their understanding of the learning materials (i.e., the video lecture). They were given space to type notes while watching the video lecture. To encourage students' helping obligatory [15], students were deliberately told that "your notes will help the student significantly in getting their answers correct. The better notes you take, the more the student will benefit from it".

In the self-regulated learning condition, students were presented with the exact same materials, except that the letter and the notes they wrote were directed inward rather than directed outward to their peers. Specifically, students were told to write a letter to encourage themselves, and to take notes for themselves. To ensure that the meta-cognition on their self-regulation and self-determination was activated, they were told that "your notes will help you significantly in getting your answers correct. The better notes you take, the more you will benefit from it".

After the experimental manipulation, all students took another version of the quiz on stoichiometry (post-test). The quiz questions for pre- and post-test were verified to be of a similar level (see materials design section below). Finally, students were directed to answer some demographic questions (e.g., age, gender, year in college), and were debriefed. Table 1 shows a summary of the procedure of the study.

Table 1. Experimental procedures and approximate time taken to complete the tasks.

\begin{tabular}{lll}
\hline Study Phase & Content & Approx. Time \\
\hline Pre-test & Pre-test Stoichiometry Quiz & $10 \mathrm{~min}$ \\
Experimental manipulation & $\begin{array}{l}\text { Random assignment to conditions } \\
\text { and video lecture }\end{array}$ & $25 \mathrm{~min}$ \\
Post-test & Post-test Stoichiometry Quiz & $15 \mathrm{~min}$ \\
\hline
\end{tabular}

Before the execution of the study, the sample size was calculated a priori using $G^{*}$ Power 3.1.9.5 [39] using the criteria of small effect size (0.25), alpha value of 0.05, and power of 0.95 , resulting in the desired sample size of at least 76. A priori calculation of the sample is crucial to avoid under-power studies. To account for attrition, we collected more samples than the minimum sample requirement. A total of 114 participants consented to participate. Among these participants, 100 of them completed the study.

In the final sample of 100 participants, most of them were freshmen (63\%), followed by sophomores (13\%), Junior (11\%), and then seniors and above (13\%). Average age was 19.91 $(S D=2.93)$. A little over half of the participants identified themselves as female $(59 \%)$, with the rest identifying themselves as male (41\%). Nearly half of the participants were assigned to the social presence condition (46\%), with the rest of the students randomly assigned to the self-regulated learning condition (54\%).

Students in the participant pool enrolled in different majors (science, liberal arts, engineering, nursing, and health, etc.). However, many of them are required to take introductory chemistry because of the college requirements. Most students have not taken any college-level chemistry courses (59\%) or have taken only one college-level chemistry 
course $(29 \%)$. The student composition is similar to a normal introductory chemistry class taught at the same institution.

\subsection{Materials Design}

Chemistry learning materials and quiz questions were developed by the second author who has experiences teaching introductory chemistry and the fourth author, a research assistant. A screenshot of the micro-lecture is shown in Figure 1. In the video lecture, key concepts and examples of balancing equations were introduced. The video lasted around $13 \mathrm{~min}$ [40]. This kind of micro-lecture was suggested to be an effective tool for students to learn chemistry online [41]. Chunking information into micro-lectures was also suggested to be an effective way to teach students stoichiometry and to prevent students' cognitive overload [42].

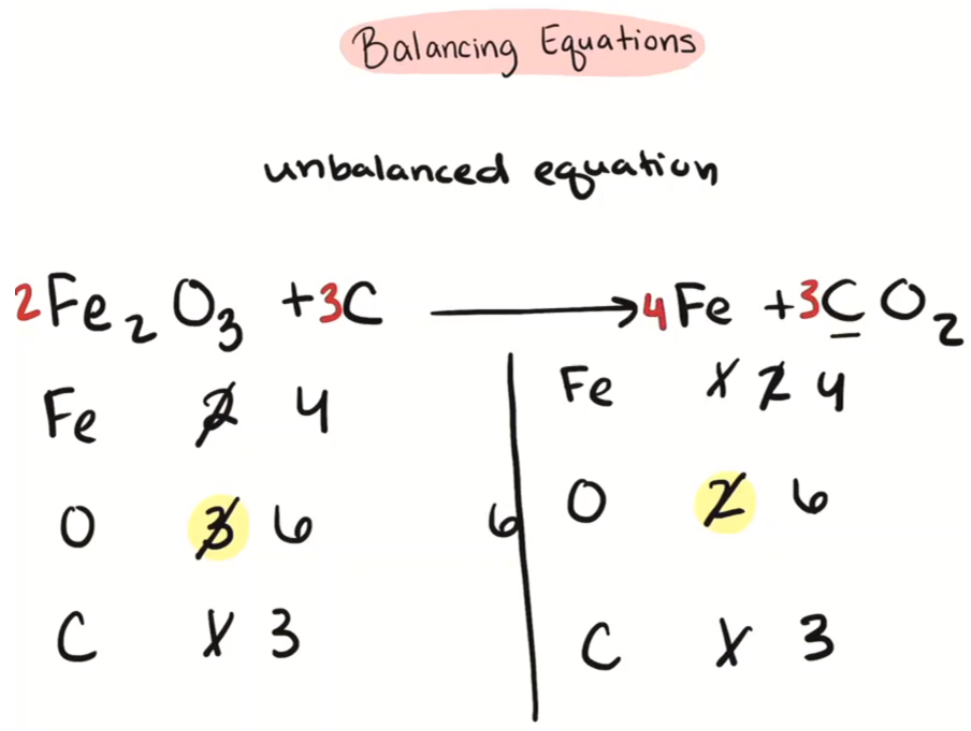

Figure 1. A screenshot of the micro-lecture on balancing equations.

To test students' understanding of stoichiometry, quiz questions were developed based on the difficulty levels of the questions (i.e., easy, medium, difficult). In both pre- and post-tests, students were given three easy questions, three medium questions, and three difficult questions. The questions sorted by difficulty level are available for download in the Supporting Information. A sample of the quiz questions was shown in Figure 2.

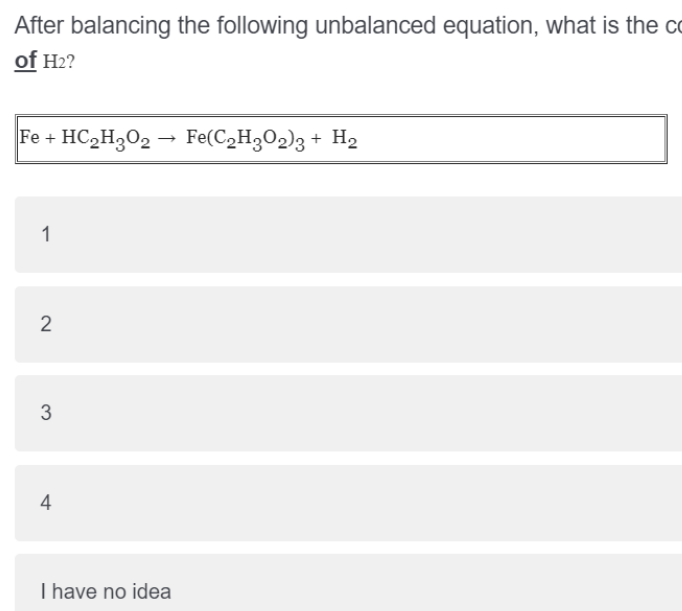

Figure 2. A screenshot of the quiz question. 
For the exploratory purpose and to understand the students' profile of our sample, in addition to the quiz questions, we also surveyed students' interests in learning chemistry and anxiety towards learning chemistry, both before and after the micro-lecture. Interests in learning chemistry were measured using two items from the Modified Attitudes toward Science Inventory (mASI) [43], including "Chemistry is something which I enjoy very much" and "Chemistry is one of my favorite subjects" and one self-constructed item on career interest, "I want to pursue a career that involves chemistry/science". Cronbach's alpha for the interests in learning chemistry measurement was 0.88 (pre-test) and 0.89 (posttest), indicating high reliability of the measure. For anxiety towards learning chemistry, students were asked to report their level of anxiety in taking a chemistry course and learning chemistry. Nine items were adapted from the Abbreviated Mathematics Anxiety Rating Scales (AMAS) [44]. Sample items were "thinking about an upcoming chemistry test one day before", "watching a teacher work a chemistry equation on the blackboard", and "taking an examination in a chemistry course". Cronbach's alpha for the anxiety towards learning chemistry measurement was 0.90 (pre-test) and 0.91 (post-test), indicating high reliability of the measure. All items were rated on a 6-point Likert scale from 1 (strongly disagree) to 6 (strongly agree).

Students were asked to indicate, out of a 6-point Likert scale, whether they would rate the video lecture as clear, easy, concise, helpful, interesting, or informative. A mean score for the video ratings was computed by averaging students' ratings across these six items. Cronbach's alpha for the video rating scale was 0.93 ,, showing the high reliability of the measure.

\subsection{Data Analysis Plan}

This study employed a 2 (between-subject: conditions) $\times 2$ (within-subject: time/preand post-test) mixed design. To analyze the data, first, descriptive statistics, including students' average quiz scores across conditions and time, students' interests in chemistry, anxiety towards learning chemistry, and average ratings of the video lecture were computed and reported.

Next, to test the main research question, whether students in the social presence condition have a better or worse quiz score improvement than students in the self-regulated learning condition, linear mixed modeling was used. The commonly used repeated measure ANOVA was not chosen in this case because it has been found to have limitations, such as the easy violation of sampling distribution [45] and inadequacy to detect test bias [46]. Instead, mixed modeling is recommended in comparing sample means across different groups [47]. Another advantage of using a generalized linear mixed model is that it accounts for the random variation in each participant by including a random intercept for each participant in the data (instead of assuming equal slopes in all participants). The effect of the experimental conditions on the students' quiz score improvement was calculated using the following equation:

$$
y=\beta_{1} x_{1}+\beta_{2} x_{2}+\beta_{3} x_{1} x_{2}+b_{1} z_{1}+\epsilon
$$

where $y$ is the learning effect (i.e. quiz scores improvement), $\beta_{1}$ and $x_{1}$ are the fixed effect coefficient and regressor of conditions, $\beta_{2}$ and $x_{2}$ are the fixed effect coefficient and regressor of time (pre vs. post), $\beta_{3}$ and $x_{1} x_{2}$ are the coefficient and regressor of the interaction of conditions and time, and $b_{1}$ and $z_{1}$ are the random-effect coefficient and regressor for individual participants and $\epsilon$ the error term. The analysis was performed on R3.5.1 [48] using the package lme4 [49]. An alpha of 0.05 was used as a cutoff value for statistical significance. A significant interaction effect $\left(\beta_{3} x_{1} x_{2}\right.$, condition $\times$ time $)$ would indicate that students across the two conditions were different in their quiz score improvement. A post-hoc sensitivity analysis using linear mixed model was conducted using the package emmeans to unpack the significant mean differences across groups (social presence vs. self-regulated learning) and across time (pre vs. post). 


\section{Results}

\subsection{Descriptive Statistics}

For exploratory purposes, and to understand our sampled students' profile, descriptive statistics of students' interests and anxiety in chemistry were analyzed. Specifically, students' interests in learning chemistry were low, both before and after the experiment $\left(M_{\text {pre }}=1.86, S D_{\text {pre }}=1.09 ; M_{\text {post }}=1.85, S D_{\text {post }}=1.11\right)$. There were no significant differences between students' interests in learning chemistry before and after the experiment, or between the two experimental conditions. Students' anxiety towards learning chemistry was moderate before the experiment $\left(M_{\text {pre }}=3.61, S D_{\text {pre }}=1.56 ; M_{\text {post }}=2.89\right.$, $S D_{\text {post }}=0.89$ ). Although the mean of students' anxiety towards learning chemistry was much lower in the post-test, no significant difference was found before and after the experiment, or between the two experimental conditions. However, this was expected, because it is unlikely that students' interests and anxiety in learning chemistry can be changed by merely attending a 13-min micro-lecture.

Table 2 shows the means and standard deviations of students' quiz scores (out of 9 points possible) by conditions and time. In general, students performed poorly in the pre-test in both conditions, with an average correct percentage of less than $40 \%$. Separate paired-sample $t$-tests were used to test students' improvement before and after the experiment. As shown in Table 2, our findings showed that both conditions were effective in improving students' stoichiometry quiz scores. Specifically, students showed significant improvement in the overall sample, $t(99)=9.79, p<0.001$, and in both the social presence condition, $t(53)=8.31, p<0.001$, and in the self-regulated learning condition, $t(45)=5.75, p<0.001$. On average, students rated the micro-lecture positively $(M=4.56$ (out of 6 points), $S D=1.23$ ).

Table 2. Means and Standard Deviations of Students' Stoichiometry Quiz Scores by Conditions and Time.

\begin{tabular}{|c|c|c|c|c|c|}
\hline & $\begin{array}{l}\text { Pre-Test } \\
M(S D)\end{array}$ & $\begin{array}{l}\text { Post-Test } \\
M(S D)\end{array}$ & $t^{a}$ & $d f$ & $p$ \\
\hline Social Presence Condition & $3.41(3.11)$ & $5.57(3.27)$ & 9.79 & 99 & $<0.001$ \\
\hline Self-Regulated Learning Condition & $3.04(2.68)$ & $6.83(2.60)$ & 8.31 & 53 & $<0.001$ \\
\hline Overall Sample & $3.21(2.87)$ & $6.25(2.98)$ & 5.75 & 45 & $<0.001$ \\
\hline
\end{tabular}

${ }^{a}$ Pre-test and post-test mean difference was tested using separate paired-sample $t$-test.

\subsection{Testing Main Research Question}

Next, to answer the main research question, that is, whether students in the social presence condition have a better or worse quiz score improvement than have students in the self-regulated learning condition, a linear mixed model analysis was conducted. Results showed that the main effect of condition was not significant, $\beta_{1}=0.38$, $S E_{\beta_{1}}=0.58, t_{\beta_{1}}=0.65,95 \% C I[-0.76,1.51]$, but the main effect of time was significant, $\beta_{2}=3.76, S E_{\beta_{2}}=0.41, t_{\beta_{2}}=9.27,95 \% C I[2.99,4.60]$, indicating that overall, participants post-test scores were significantly higher than pre-test scores. The interaction term of condition $\times$ time was found to be significant, $\beta_{3}=-1.64, S E_{\beta_{3}}=0.60, t_{\beta_{3}}=-2.72$, $95 \%$ CI $[-2.83,-0.46]$. A post-hoc sensitivity analysis was conducted to unfold the pattern of interaction. Results showed that, while students in two conditions were not different in pre-test $(b=-0.38, S E=0.58, t=-0.65, p=0.520)$, students in self-regulated learning condition significantly improved more than did students in the social presence condition $(b=1.27, S E=0.58, t=2.17, p=0.031)$. In other words, self-regulation strategy appeared to be more effective than social presence strategy in our current study. Figure 3 shows the increase of students' quiz scores across conditions and time. As shown in Figure 3, the slope (indicating improvement across time) was steeper in the self-regulated learning condition than in the social presence condition. 


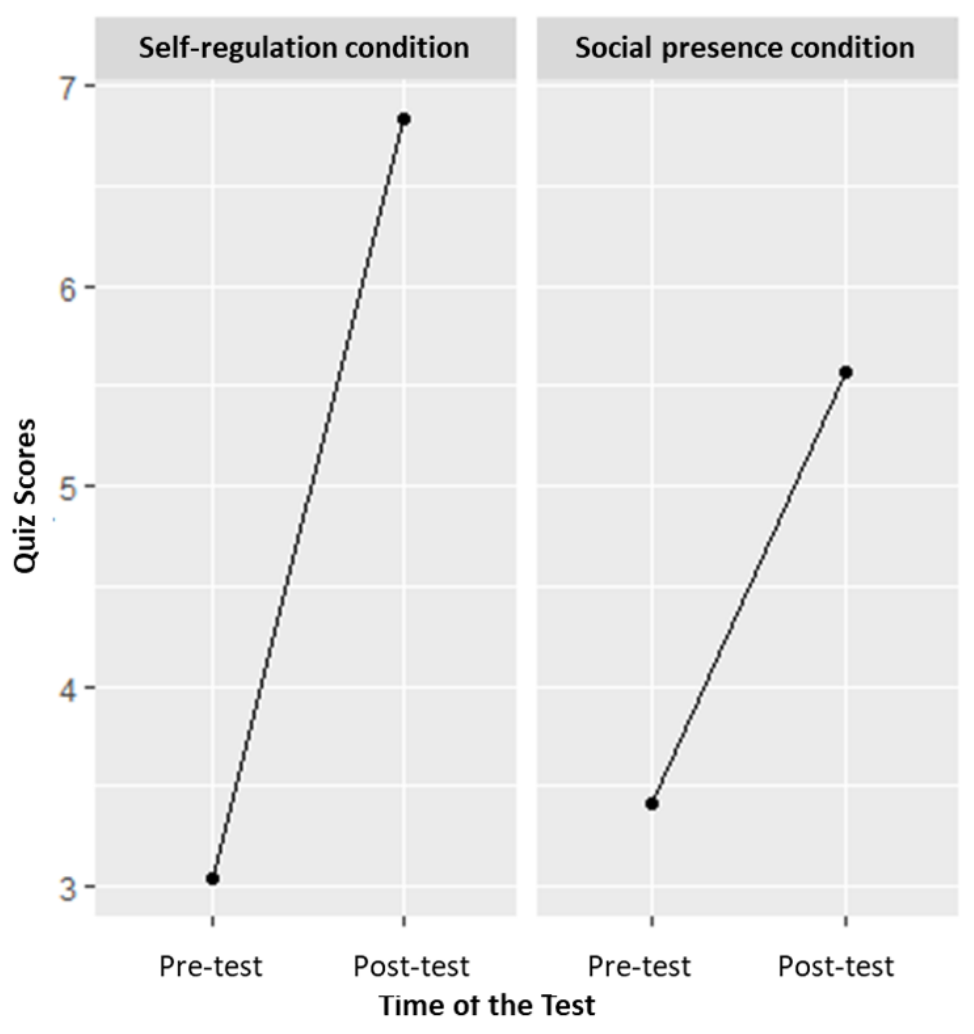

Figure 3. Increase of students' quiz scores across conditions and time.

\section{Discussion}

\subsection{Implications for Chemistry Learning}

In this study, we successfully designed two experimental conditions using two sets of sociocognitive theories, social presence theory and self-oriented theories (selfdetermination and self-regulated learning theory). We then tested the effect of these two learning strategies on students' online introductory chemistry learning outcomes, using stoichiometry as the subject of the learning experiment. A double-blind 2 (between-subject: conditions) $\times 2$ (within-subject: time) randomized experimental design was employed, a linear mixed modeling analytic strategy was employed to test the research question: Do students in the social presence condition have a better or worse quiz score than have students in the self-regulation condition?

Our findings showed that both conditions resulted in significant improvements in students' quiz scores after the introduction of the learning strategies. Specifically, when students engaged in helping other students and experienced the virtual presence of another peer in the learning process (i.e., social presence condition) and when students engaged in self-determination and regulation (i.e., engaging in self-recording/note-taking, and selfmotivation and goal-setting), their stoichiometry scores significantly improved under both conditions. However, our linear mixed modeling results showed that between the two strategies, self-determination/self-regulation strategy appeared to be more effective in increasing students' learning outcomes in an online introductory chemistry classroom. Our findings are consistent with another randomized experimental study in chemistry which showed that students' learning occurred mostly in the self-learning/self-regulation phase of a flipped classroom, rather than during the social presence or peer interaction period [21]. Specifically, the researchers in that study only found a significant increase in organic chemistry knowledge after students engaged in self-learning, and they found no significant increase in organic chemistry knowledge after students learned with peers. Although their study differed from ours in the study design, their findings were in alignment with our study, which showed that in chemistry learning, the role of self might be much more 
important than the role of connecting with others. These findings do not undermine the importance of research findings of peer-learning; rather, these suggest that chemical educational research should not overemphasize the role of peer and neglect the role of self in learning.

The current study has several contributions. Our experimental conditions were carefully crafted so that the two experimental groups were not different except for the independent variable manipulated. This design had high internal validity and significantly reduced confounding in the experimental design. Classroom studies are helpful in understanding students in the context of the class and the instructors; however, classroom studies are often conducted by instructors who have knowledge of the experimental hypotheses (i.e., potential experimental bias due to non-blinded study). The variations across different classes, years, and cohorts could also introduce confounding and extraneous variables to the study design. Therefore, conducting a double-blind randomized experimental study like our current study could greatly complement existing classroom studies in chemical education. Our study also contributed to the understanding of online learning specific to chemistry contexts. Understanding online learning in chemistry is crucial in sustaining students' quality of learning, especially given the recent increase in distance learning or remote teaching. As mentioned earlier, the current study was conducted during COVID-19's transition from the traditional in-person classroom to online learning. Although it is not the goal of this study to understand teaching strategies specifically relating to COVID-19, this study successfully showed that in an online environment where students may get distracted and lose focus and motivation, engaging students meta-cognitively to consider their responsibilities and role in self-planning, self-recording, and self-determination, and their ability to successfully help to increase students' learning outcome.

It should also be noted that the students who we tested in this sample were generally uninterested in chemistry (rated interests in chemistry as an average of 1.85 out of a 6-point scale) and moderately anxious about learning chemistry in college (3.61 out of a 6-point scale). Therefore, both strategies introduced in this study, and particularly the self-regulation strategy appeared to be effective in helping students who may find chemistry to be uninteresting or difficult. This is very important in introductory chemistry, especially because introductory chemistry is often a required course of students from not only chemistry but also other science, engineering, and health science students. Students ${ }^{\prime}$ decision to major in chemistry can be greatly influenced by their experience in introductory chemistry. Therefore, the strategies and the theoretical framework that we introduced in this study could potentially benefit the success and retention of students.

\subsection{Limitation and Future Directions}

This study is not without limitations. First, this study is an experimental study conducted in a virtual setting that models after chemistry learning experiences. It is not an actual chemistry classroom and involves only learning a subtopic in stoichiometry through a micro-lecture. However, conducting empirical studies in a well-controlled experimental setting is crucial in eliminating confounding and increasing internal validity. Future studies may complement the current study by conducting it in an actual chemistry class over a period of a semester. Second, this study only involves two strategies, each developed from one of the theoretical frameworks. Therefore, based on these experimental findings, future empirical studies may expand to examine the effectiveness of specific self-regulation strategies in chemistry online course design, such as incorporating self-assessment and selfevaluation [33] elements, encouraging goal-setting [38], and promoting self-planning [50].

In addition to research studies, with the rising popularity and the need of developing online open educational resources (OER), future chemistry OER can be designed with these self-determination and self-regulation strategies in mind. For example, these OER texts or web tools may include a feedback system in which students can assess their progress and get feedback on what they need to improve. An OER tool may be created to help students self-manage their own progress on learning essential concepts in chemistry. Such a tool 
may include a checklist feature for students to monitor their learning progress. In addition, to enhance self-instruction and self-recording, a tool that allows students to easily take notes and organize notes may help students increase in chemistry learning outcomes.

\section{Conclusions}

In conclusion, guided by two socio-cognitive theoretical frameworks, our randomized experimental study revealed that self-oriented learning might be more important than other-oriented learning in the context of an online chemistry learning environment. Although our findings do not infer that peers are not important in students' chemistry learning, our findings emphasize the importance of understanding ways to increase students' self-determined attitude and self-regulated behaviors in chemistry learning. The recent COVID-19 pandemic has caused a global need to move chemistry education to an online environment. Our study helps to shed light upon components to be considered when designing an online chemistry course, especially an introductory course that often includes beginners who may be taking the course as a requirement and may be uninterested or unmotivated.

Author Contributions: Conceptualization, M.L., and Y.W.; methodology, M.L., and Y.W.; validation, M.L., Y.W., and H.N.S.; formal analysis, M.L.; investigation, M.L., N.T.; resources, M.L., Y.W., and N.T.; data curation, M.L.; writing—original draft preparation, M.L.; writing—review and editing, M.L., Y.W. and H.N.S.; visualization, M.L. and Y.W.; supervision, M.L. and Y.W.; project administration, M.L.; funding acquisition, M.L. and Y.W. All authors have read and agreed to the published version of the manuscript.

Funding: This research was funded by the Louisiana Board of Regents (LEQSF(2019-22)-RD-A-23 and LEQSF(2017-20)-RD-A-23).

Institutional Review Board Statement: The study was conducted according to the guidelines of the Declaration of Helsinki, and approved by the Institutional Review Board (or Ethics Committee) of the University of Louisiana at LAfayette (protocol code SP20-109 PSYC and date of approval: 7 April 2020).

Informed Consent Statement: Informed consent was obtained from all participants involved in the study.

Data Availability Statement: The data presented in this study are available on request from the corresponding author.

Conflicts of Interest: The authors declare no conflict of interest.

\section{References}

1. Huang, J. Successes and Challenges: Online Teaching and Learning of Chemistry in Higher Education in China in the Time of COVID-19. J. Chem. Educ. 2020, 97, 2810-2814. [CrossRef]

2. Gillett-Swan, J. The challenges of online learning: Supporting and engaging the isolated learner. J. Learn. Des. 2017, 10, $20-30$. [CrossRef]

3. Ruey, S. A case study of constructivist instructional strategies for adult online learning. Br. J. Educ. Technol. 2010, 41, 706-720. [CrossRef]

4. Chen, K.C.; Jang, S.J. Motivation in online learning: Testing a model of self-determination theory. Comput. Hum. Behav. 2010, 26, 741-752. [CrossRef]

5. Short, J.; Williams, E.; Christie, B. The Social Psychology of Telecommunications; John Wiley \& Sons: Hoboken, NJ, USA, 1976.

6. Tu, C.H. On-line learning migration: From social learning theory to social presence theory in a CMC environment. J. Netw. Comput. Appl. 2000, 23, 27-37. [CrossRef]

7. Lu, B.; Fan, W.; Zhou, M. Social presence, trust, and social commerce purchase intention: An empirical research. Comput. Hum. Behav. 2016, 56, 225-237. [CrossRef]

8. Cobb, S.C. Social presence and online learning: A current view from a research perspective. J. Interact. Online Learn. 2009, 8, 241-254.

9. Sher, A. Assessing the relationship of student-instructor and student-student interaction to student learning and satisfaction in web-based online learning environment. J. Interact. Online Learn. 2009, 8, 102-120.

10. Chen, P.S.D.; Lambert, A.D.; Guidry, K.R. Engaging online learners: The impact of Web-based learning technology on college student engagement. Comput. Educ. 2010, 54, 1222-1232. [CrossRef] 
11. Crisp, R.J.; Turner, R.N. The Imagined Contact Hypothesis, 1st ed.; Elsevier Inc.: Amsterdam, The Netherlands, 2012; Volume 46, pp. 125-182. [CrossRef]

12. Perera, V.L.; Wei, T.; Mlsna, D.A. Impact of Peer-Focused Recitation to Enhance Student Success in General Chemistry. J. Chem. Educ. 2019, 96, 1600-1608. [CrossRef]

13. Stephenson, N.S.; Miller, I.R.; Sadler-Mcknight, N.P. Impact of Peer-Led Team Learning and the Science Writing and Workshop Template on the Critical Thinking Skills of First-Year Chemistry Students. J. Chem. Educ. 2019, 96, 841-849. [CrossRef]

14. Frey, R.F.; Fink, A.; Cahill, M.J.; McDaniel, M.A.; Solomon, E.D. Peer-Led Team Learning in General Chemistry I: Interactions with Identity, Academic Preparation, and a Course-Based Intervention. J. Chem. Educ. 2018, 95, 2103-2113. [CrossRef]

15. Shibley, I.A.; Zimmaro, D.M. The influence of collaborative learning on student attitudes and performance in an introductory chemistry laboratory. J. Chem. Educ. 2002, 79, 745. [CrossRef]

16. Gafney, L.; Varma-Nelson, P. Evaluating peer-led team learning: A study of long-term effects on former workshop peer leaders. J. Chem. Educ. 2007, 84, 535-539. [CrossRef]

17. Bokosmaty, R.; Bridgeman, A.; Muir, M. Using a Partially Flipped Learning Model to Teach First Year Undergraduate Chemistry. J. Chem. Educ. 2019, 96, 629-639. [CrossRef]

18. Schultz, D.; Duffield, S.; Rasmussen, S.C.; Wageman, J. Effects of the flipped classroom model on student performance for advanced placement high school chemistry students. J. Chem. Educ. 2014, 91, 1334-1339. [CrossRef]

19. Hand, B.; Yang, O.E.M.; Bruxvoort, C. Using writing-to-learn science strategies to improve year 11 students' understandings of stoichiometry. Int. J. Sci. Math. Educ. 2007, 5, 125-143. [CrossRef]

20. Yeager, D.S.; Hanselman, P.; Walton, G.M.; Murray, J.S.; Crosnoe, R.; Muller, C.; Tipton, E.; Schneider, B.; Hulleman, C.S.; Hinojosa, C.P.; et al. A national experiment reveals where a growth mindset improves achievement. Nature 2019, 573, 364-369. [CrossRef]

21. Casselman, M.D.; Atit, K.; Henbest, G.; Guregyan, C.; Mortezaei, K.; Eichler, J.F. Dissecting the flipped classroom: Using a randomized controlled trial experiment to determine when student learning occurs. J. Chem. Educ. 2020, 97, 27-35. [CrossRef]

22. Deci, E.L.; Vansteenkiste, M. Self-Determination theory and basic need satisfaction: Understanding human development in positive psychology. Ric. Psicol. 2004, 27, 23-40.

23. Schüler, J.; Baumann, N.; Chasiotis, A.; Bender, M.; Baum, I. Implicit motives and basic psychological needs. J. Personal. 2019, 87, 37-55. [CrossRef] [PubMed]

24. Deci, E.L.; Ryan, R.M. Conceptualizations of intrinsic motivation and self-determination. In Intrinsic Motivation and SelfDetermination in Human Behavior; Springer: Berlin/Heidelberg, Germany, 1985; pp. 11-40.

25. Ryan, R.M.; Deci, E.L. Self-determination theory and the facilitation of intrinsic motivation, social development, and well-being. Am. Psychol. 2000, 55, 68. [CrossRef]

26. Baumeister, R.F.; Leary, M.R. The need to belong: Desire for interpersonal attachments as a fundamental human motivation. Psychol. Bull. 1995, 117, 497. [CrossRef] [PubMed]

27. Deci, E.L.; Ryan, R.M.; Vallerand, R.J.; Pelletier, L.G. Motivation and Education: The Self-Determination Perspective. Educ. Psychol. 1991, 26, 325-346. [CrossRef]

28. Jang, H. Supporting Students' Motivation, Engagement, and Learning During an Uninteresting Activity. J. Educ. Psychol. 2008, 100, 798-811. [CrossRef]

29. Sjöblom, K.; Mälkki, K.; Sandström, N.; Lonka, K. Does Physical Environment Contribute To Basic Psychological Needs? A Self-Determination Theory Perspective on Learning in the Chemistry Laboratory. Frontline Learn. Res. 2016, 4, 17-39. [CrossRef]

30. Coppola, B.P. Progress in practice: Using concepts from motivational and self-regulated learning research to improve chemistry instruction. New Dir. Teach. Learn. 1995, 1995, 87-96. [CrossRef]

31. Panadero, E. A review of self-regulated learning: Six models and four directions for research. Front. Psychol. 2017, 8, 1-28. [CrossRef]

32. Zimmerman, B.J. Attaining self-regulation: A social cognitive perspective. In Handbook of Self-Regulation; Elsevier: Amsterdam, The Netherlands, 2000; pp. 13-39.

33. Panadero, E.; Jonsson, A.; Botella, J. Effects of self-assessment on self-regulated learning and self-efficacy: Four meta-analyses. Educ. Res. Rev. 2017, 22, 74-98. [CrossRef]

34. Lawrie, G.A.; Schultz, M.; Bailey, C.H.; Al Mamun, M.A.; Micallef, A.S.; Williams, M.; Wright, A.H. Development of Scaffolded Online Modules to Support Self-Regulated Learning in Chemistry Concepts. ACS Symp. Ser. $2016,1235,1-21$. doi:10.1021/bk-2016-1235.ch001. [CrossRef]

35. Priyambodo, E.; Sulistyani, S. The Effect of Multimedia Based Learning in Chemistry Teaching and Learning on Students' Self-Regulated Learning. J. Educ. Learn. 2014, 8, 363. [CrossRef]

36. Eklund, B.; Prat-Resina, X. ChemEd X data: Exposing students to open scientific data for higher-order thinking and self-regulated learning. J. Chem. Educ. 2014, 91, 1501-1504. [CrossRef]

37. Hermanns, J.; Schmidt, B. Developing and Applying Stepped Supporting Tools in Organic Chemistry to Promote Students' Self-Regulated Learning. J. Chem. Educ. 2019, 96, 47-52. [CrossRef]

38. Littlejohn, A.; Hood, N.; Milligan, C.; Mustain, P. Learning in MOOCs: Motivations and self-regulated learning in MOOCs. Internet High. Educ. 2016, 29, 40-48. [CrossRef]

39. Faul, F.; Erdfelder, E.; Buchner, A.; Lang, A.G. Statistical power analyses using G* Power 3.1: Tests for correlation and regression analyses. Behav. Res. Methods 2009, 41, 1149-1160. [CrossRef] 
40. Turki, N. Balancing Equation-Chemistry Mini-Lecture. 2020. Available online: https:/ /www.youtube.com/watch?v=Z1kucSxCdo (accessed on 25 Februaray 2021).

41. Mu, D.; Liu, C.L.; Luo, H.N. The Expand Application of Micro-lecture in Flipped Classroom in the Reform of Bilingual Teaching of Physical Chemistry Experiment-Taking Physical Chemistry Experiment Bilingual Course in Zaozhuang University as an Example. In Proceedings of the 2nd International Seminar on Education Research and Social Science (ISERSS 2019), Kuala Lumpur, Malaysia, 25-27 May 2019; Atlantis Press: Paris, France, 2019; pp. 228-231. [CrossRef]

42. Krieger, C.R. Stoogiometry: A cognitive approach to teaching stoichiometry. J. Chem. Educ. 1997, 74, 306. [CrossRef]

43. Weinburgh, M.H.; Steele, D. The Modified Attitudes Toward Science Inventory: Developing an Instrument To Be Used With Fifth Grade Urban Students. J. Women Minor. Sci. Eng. 2000, 6, 8. [CrossRef]

44. Hopko, D.R.; Mahadevan, R.; Bare, R.L.; Hunt, M.K. The Abbreviated Math Anxiety Scale (AMAS): Construction, validity, and reliability. Assessment 2003, 10, 178-182. [CrossRef]

45. Chang, C.H.; Pal, N.; Lim, W.K.; Lin, J.J. Comparing several population means: A parametric bootstrap method, and its comparison with usual ANOVA F test as well as ANOM. Comput. Stat. 2010, 25, 71-95. [CrossRef]

46. Camilli, G.; Shepard, L.A. The inadequacy of ANOVA for detecting test bias. J. Educ. Stat. 1987, 12, 87-99. [CrossRef]

47. Jaeger, T.F. Categorical data analysis: Away from ANOVAs (transformation or not) and towards logit mixed models. J. Mem. Lang. 2008, 59, 434-446. [CrossRef] [PubMed]

48. R Core Team. R: A Language and Environment for Statistical Computing; R Foundation for Statistical Computing: Vienna, Austria, 2018.

49. Bates, D.; Mächler, M.; Bolker, B.; Walker, S. Fitting Linear Mixed-Effects Models Using lme4. J. Stat. Softw. 2015, 67, 1-48. [CrossRef]

50. Khiat, H. Academic performance and the practice of self-directed learning: The adult student perspective. J. Furth. High. Educ. 2017, 41, 44-59. [CrossRef] 